\title{
Manuscripts in Transition. Recycling Manuscripts, Texts and Images, Edited by Brigitte Dekeyzer and Jan Van der Stock
}

\section{Maria Colombo Timelli}

\author{
(2) OpenEdition \\ Journals \\ Edizione digitale \\ URL: http://journals.openedition.org/studifrancesi/8832 \\ DOI: 10.4000/studifrancesi.8832 \\ ISSN: 2421-5856

\section{Editore} \\ Rosenberg \& Sellier

\section{Edizione cartacea} \\ Data di pubblicazione: 1 octobre 2008 \\ Paginazione: $432-433$ \\ ISSN: 0039-2944

\section{Notizia bibliografica digitale} \\ Maria Colombo Timelli, «Manuscripts in Transition. Recycling Manuscripts, Texts and Images, Edited by \\ Brigitte Dekeyzer and Jan Van der Stock», Studi Francesi [Online], 155 (LII | II) | 2008, online dal 30 \\ novembre 2015, consultato il 12 janvier 2021. URL: http://journals.openedition.org/studifrancesi/8832 \\ ; DOI: https://doi.org/10.4000/studifrancesi.8832
}

Questo documento è stato generato automaticamente il 12 janvier 2021.

\section{cc) (†)}

Studi Francesi è distribuita con Licenza Creative Commons Attribuzione - Non commerciale - Non opere derivate 4.0 Internazionale. 


\title{
Manuscripts in Transition. Recycling Manuscripts, Texts and Images, Edited by Brigitte Dekeyzer and Jan Van der Stock
}

\author{
Maria Colombo Timelli
}

\section{NOTIZIA}

Manuscripts in Transition. Recycling Manuscripts, Texts and Images, Edited by Brigitte DEKEYZER and Jan VAN DER STOCK, Paris-Leuven-Dudley, MA, Peeters, 2005 («Corpus of Illuminated Manuscripts», 15).

1 Albert CHÂTelet, La vision de l'antiquité de Jacques Coene, pp. 235-239. Artista della fine del XIV secolo, Jacques Coene ha illustrato il Des claires et nobles femmes di Boccaccio, ms. fr. 12420 della BnF: conformemente alle abitudini del tempo, le divinità appaiono attualizzate sulle realtà della corte degli anni 1401-1403.

2 Lieve WATTEEUW, Documentation concerning the $15^{\text {th }}$-Century Care of Manuscripts in the Burgundian Library, pp. 241-251. È eccezionale che si conosca l'identità di un restauratore/rilegatore di libri del tardo Medio Evo: è però quanto accade per Antoine de Gavere, il cui nome appare nei conti del 1498 e del 1504 della corte di Borgogna; L.W. studia in particolare il restauro del manoscritto Bruxelles, KBR 10176-10178, che conserva i Pélerinages di Guillaume de Digulleville.

3 Frédérique JOHAN, Un exemple de réemploi stylistique et pictural emprunté au Maître de Wavrin: "Le Petit Jehan de Saintré", pp. 301-307. Il manoscritto KBR 9547 del Saintré contiene 77 miniature all'acquerello il cui stile richiama quello del Maitre de Wavrin: peraltro, la trascuratezza nell'esecuzione porterebbe, nonostante la somiglianza di alcuni particolari o scene con le illustrazioni di altri romanzi, ad escludere questa 
attribuzione. F.J. sottolinea anche la cattiva qualità delle ultime illustrazioni, che imputa alla fretta di concludere il ciclo iconografico.

4 Jacques charles LEMAIRE, Le manuscrit Paris, BnF, Ms. fr. 12601 est-il sorti de l'atelier du Maitre de Wavrin?, pp. 309-315. Questo manoscritto dell'Istoire de la destruction de Troye la grant di Jacques Milet non contiene elementi codicologici né testuali che consentano di collocarlo nelle regioni settentrionali della Francia. È semmai la decorazione - 392 miniature all'acquerello - che dimostra l'influenza esercitata dal Maître de Wavrin anche al di fuori della sua regione d'origine.

5 Anne DuboIs, Interpénétration des manuscrits et des incunables. L'exemple de Lyon et du Chantilly, Musée Condé, Ms. 833-834, pp. 317-323. Il ms. 833-834 di Chantilly, che tramanda testo latino e traduzione francese dei Facta et dicta memorabilia di Valerio Massimo, fu trascritto da Jean Tybonnier, copista lionese, sulla base di due stampe precedenti, una milanese per il testo originale, una neerlandese per la versione francese. L'esame delle illustrazioni dimostra poi che lo stesso manoscritto funse da modello per altri due incunaboli lionesi di Matthias Husz (1485 e 1489), quindi per un'edizione di Antoine Vérard (1499-1500). 